\title{
Review
}

Journal of Innate

Immunity
J Innate Immun 2011;3:395-402

DOI: $\underline{10.1159 / 000324400}$
Received: October 14, 2010

Accepted after revision: January 18, 2011 Published online: March 12, 2011

\section{The Role of Natural Killer Cells in Human Solid Organ and Tissue Transplantation}

\author{
Jean Villard \\ Transplantation Immunology Unit, Division of Immunology and Allergy, Division of Laboratory Medicine, \\ Geneva University Hospital and Medical School, Geneva, Switzerland
}

\begin{abstract}
Key Words
Natural killer cells $\cdot$ Tissue transplantation $\cdot$ Killer cell immunoglobulin-like receptor/human leukocyte antigen • Solid organ transplantation - Alloimmune response
\end{abstract}

\begin{abstract}
During the last decade, considerable progress was made in the understanding of the natural killer (NK) cell mechanisms of action, especially in the processes of target cell recognition and lysis. These breakthroughs have aroused large interest in the role of NK cells in the pathogenesis of a variety of diseases. In hematopoietic stem cell transplantation, NK cells have been shown to play a significant role in the graft-versus-leukemic effect leading to protocols of cell therapy using amplified NK cells after transplantation. In human solid organ transplantation (SOT), the role of NK cells was controversial due to conflicting clinical and animal model data. NK cells have been shown to exacerbate T-cell responses during rejection, but also to promote tolerance induction under immunosuppression. The role of NK cells is of special interest in SOT because in contrast to T cells, the effect of immunosuppressive drugs on NK cells is modest, at least in vivo. Recent publications demonstrated the importance of killer cell immunoglobulin-like receptor/human leukocyte antigen genotypes to predict the risk of rejection and to prevent cytomegalovirus infection/reactivation. NK cell subpopulations could have different alloreactivity or immunomodulatory
\end{abstract}

potentials. Finally, an understanding of the role of NK cells in the field of embryonic stem cells and their progenitor transplantation is developing. Currently, NK cells are considered a key player in the alloimmune and anti-infectious responses after SOT and transplanted tissues.

Copyright $\odot 2011$ S. Karger AG, Basel

\section{Introduction}

In the absence of immunosuppression, transplanted solid organs are rejected by mechanisms that involve innate and adaptative immunity.

The presentation of donor antigens by recipient and donor antigen-presenting cells (APCs) induces activation and proliferation of specific alloreactive $\mathrm{T}$ cells in the lymph nodes. Alloreactive $\mathrm{T}$ cells eventually migrate to destroy the engrafted tissue. Proinflammatory cytokines like interferon (IFN)- $\gamma$ or tumor necrosis factor (TNF)- $\alpha$ are very important to mature APCs and activated T cells. Inflammation also helps cytotoxic $\mathrm{T}$ cells to destroy the graft. Thanks to immunosuppression, T cells are strongly inhibited, although it is not sufficient to prevent the progressive loss of function of the graft, and survival of the transplanted organ remains limited compared to a native organ. The cells of the innate immune system have now been accepted as an important player in the mechanisms of acute and chronic rejections by being the pro-

\section{KARGER \\ Fax +4161306 1234 \\ E-Mail karger@karger.ch}

www.karger.com (c) 2011 S. Karger AG, Basel

$1662-811 X / 11 / 0034-0395 \$ 38.00 / 0$

Accessible online at:

www.karger.com/jin
Dr. Jean Villard

Transplantation Immunology Unit, Division of Immunology and Allergy

Division of Laboratory Medicine, Geneva University Hospital and Medical School

4, Rue Gabrielle Perret-Gentil, CH-1211 Geneva 14 (Switzerland)

Tel. +41 22372 9394, E-Mail jean.villard@ @cuge.ch 
ducer of cytokines leading to inflammation and tissue injury [1]. Natural killer (NK) cells are of special interest because, in addition to cytokine production, NK cells can directly target the transplanted tissue through the balance of activating and inhibitory receptors and their ligands expressed or not expressed by the graft. In the 1980s, Kärre et al. [2] observed that tumoral cells not expressing the major histocompatibility complex class I (MHC-I) were killed preferentially by NK cells. This led to the hypothesis of the 'missing self', according to which NK cells detect MHC-I (the self) on the cell surface and kill those cells not or weakly expressing MHC-I. The discovery of inhibitory killer cell immunoglobulin-like receptors (KIRs) that bind to MHC-I antigens sustains the molecular base of their hypothesis. In solid organ transplantation (SOT), the inhibitory KIRs expressed by NK cells can bind to the corresponding MHC-I expressed by the graft which prevents NK cell activation. Absence of the cognate MHC-I ligand induces a 'missing self situation' and activated NK cells target the graft.

Based on depletion strategies, previous rodent models of organ and tissue transplantation did not convincingly attribute a significant role to NK cells in rejection. However, more recent studies demonstrate that NK cells become activated early after organ transplantation and can contribute to the cell-mediated alloresponse and acute rejection process $[3,4]$. In human SOT, an understanding of the role of NK cells is developing, with a limited number of studies addressing the question. This is the main focus of this review.

\section{NK Cell Receptors and Their Ligands in Organ Transplantation}

NK cells express a large variety of activating and inhibitory receptors that are of interest in the context of SOT. Most of the inhibitory receptors belong to the KIR family which binds to the locus B and C of MHC-I expressed by the transplanted organ or tissue. The KIR2DL1 receptor binds to different human leukocyte antigen (HLA)-C antigens included in group 2 (like HLA-Cw2, HLA-Cw4, HLA-Cw6 and HLA-Cw15, with a lysine at position 80 of their amino acid sequence). KIR2DL2 and KIR2DL3 bind to HLA-C antigens of group 1 (like HLAC1, HLA-C3, HLA-C7 and HLA-C8, with an asparagine at position 80 of their amino acid sequence). KIR3DL1 binds to HLA-B antigen included in the Bw4 group. HLA class I antigens being expressed constitutively in every cell of the graft, KIRs of the patients and HLAs of the do- nors are susceptible to induce NK cell alloreactivity. Of note, the HLA-C typing is not routinely performed in SOT, explaining the limited number of studies on KIR/ HLA.

Other NK cell ligands expressed by the graft could be of interested in the context of NK cell activity. The NKG2 family which are type II membrane glycoproteins such as C-type lectins includes NKG2A and NKG2C that bind to HLA-E and are expressed as heterodimeric forms with the invariant polypeptide CD94. Under normal circumstances, expression of the HLA-E molecule is found in most tissues that express HLA-A, HLA-B, HLA-C or HLA-G molecules including engrafted tissue [5].

NKG2D is an activating receptor that binds to MHCI-related chain A (MICA) and MICB proteins, as well as to UL16-binding protein (ULBP) molecules. Interestingly, MICA/B and ULBP1, ULBP2 and ULBP3, ligands of NKG2D, are weakly expressed but can be induced following infection or inflammation which are frequent after transplantation and can play a significant role in NK cell alloreactivity. Activating receptors also include the natural cytotoxicity receptors (NCR1, NCR2, NCR3 also called 'NKp46, NKp44 and NKp30', respectively) which belong to the immunoglobulin superfamily and are very specific to NK cells. NCRs whose ligands are not well characterized could also be of interest in the context of allogeneic transplantation [6-11].

\section{Mechanisms of NK Cell Alloreactivity}

Alloreactivity mediated by NK cells differs from that mediated by T cells. The NK cell receptors are germline encoded and, as far as we know, HLA-C or Bw4 ligands do not present specific peptides to KIRs. Alloreactivity is based on the absence of an inhibitory signal due to low or no ligand expression or to ligand mismatch with regard to the KIR/MHC status. The influence of the KIR/HLA genotype has been first demonstrated in the context of allogeneic stem cell transplantation (SCT). In mice models $[12,13]$ and in human SCTs where a KIR/HLA mismatch reduces the risk of tumor recurrence in patients with acute myelogenous leukemia, it improves the engraftment and protects against a graft-versus-host disease $[12,14]$. NK cell alloreactivity is mainly observed for haploidentical transplantations and mismatched unrelated SCTs [12, 15-17]. However, these data remain controversial and the beneficial effect of alloreactive NK cells during SCT is not confirmed by others $[18,19]$. 
The 13 genes coding for KIR are expressed in various subpopulations of NK cells, making the one individual NK cell population very heterogeneous $[6,20]$. These genes are expressed in a stochastic way recovering all NK cell subtypes. Consequently, no NK cell expresses all genes coding for KIR present in an individual genome but can express $0-4$ of these genes. The result is a diversity of NK cells having a unique KIR repertoire which could have significant influence on the level of alloreactivity.

Therefore, alloreactivity against the transplanted tissue will depend on a fine-tuned balance between activating and inhibitory receptors, i.e. KIRs, C-type lectins and the NCR family and the expression of ligands on the transplanted tissue, but also on the NK cell subpopulations that have different alloreactivity potentials. Their cytotoxic activity is mainly mediated by perforin-granzyme as well as by FasL, leading to the destruction of the engrafted tissue.

The mechanism of NK cell alloreactivity is also mediated by an indirect pathway, i.e. through the production of proinflammatory cytokines. The secretion of IFN- $\gamma$ and TNF- $\alpha$ by NK cells is likely to induce and upregulate the expression of MHC molecules and costimulatory receptors on APCs, thus promoting the maturation efficacy of professional APCs (dendritic cells and B cells) and presumably nonprofessional APCs (endothelial cells) [21] which enhance direct and indirect alloresponses by $\mathrm{T}$ cells. NK cells can also kill Foxp3+ regulatory T cells, depending on the activation status of NK cells $[18,19]$.

\section{NK Cells and Regulatory Function in Transplantation}

In addition to NK cell cytotoxicity and proinflammatory cytokine production, subsets of NK cells have immunoregulatory functions. NK cells interact with various components of the immune system, and therefore, have the potential to function as regulatory cells. While NK cells can assist in APC maturation and T-cell polarization, increasing evidence indicates that NK cells can also prevent and limit adaptive (auto-/allo-) immune responses via killing of autologous myeloid and lymphoid cells. There is evidence that NK cell cytotoxicity to recipient APCs is important in preventing allogeneic responses of T-specific cells in lymph nodes [22]. Secretion of anti-inflammatory cy tokines like transforming growth factor (TGF)- $\beta$ or interleukin (IL)-10 has been detected in subtypes of NK cells. In a mouse model, production of IL-10 in response to visceral leishmaniasis infection demonstrates clear regulatory roles for NK cells in systemic inflammation. In human patients chronically infected by hepatitis $\mathrm{C}$ virus, NK cells produced IL-10 in addition to IFN- $\gamma$ [23]. Recent data suggest that the NK cell regulatory mechanism could also be mediated by the secretion of TGF- $\beta$ by regulatory T cells that inhibited the expression of cytotoxic molecules like CD16, granzymes and by downregulation of the C-type lectin-activating receptor NKG2D [24].

Most of the NK cell regulatory functions have been documented preclinically in different murine models of infection and tumor and can potentially apply to SOT.

\section{NK Cells and SOT}

In previous experiments using the NK cell depletion strategy in animal models of transplantation, the absence of NK cells does not significantly modify the rejection of transplanted organs like the heart or liver $[25,26]$. More recently, NK cells have been shown to be crucial for graft survival. CD28-deficient mice readily reject an MHC mismatched heart allograft; in this model, rejection can be prevented by depletion of host NK cells [27]. Rag knockout mice lacking $\mathrm{T}$ and $\mathrm{B}$ cells could reject skin allografts upon activation of NK cells exposed to IL-15 [28]. Currently, there is no doubt that NK cells can contribute to acute and chronic allograft rejection in rodent models $[21,29,30]$.

In human SOT, the exploration of NK cells is much more limited. The presence of NK cells in kidney biopsy of acute cellular rejection is rare, but recent data have demonstrated that NK cells and macrophages are selectively increased in peritubular capillaries of kidney biopsies following antibody-mediated rejection situations [31]. The absence of strong evidence for the presence of NK cells in the graft does not rule out the participation of NK cells in the alloimmune reaction because a large part of NK cell activity could take place in the lymph nodes.

Analysis of the recipient's KIR typing and the MHC-I ligands of the donor has been performed in the context of liver and kidney transplantation. The absence of inhibition with the presence of an activating receptor induces the killing of the allogeneic tissue. The combination of activating or inhibitory KIRs defined by A or B haplotype and the expression of their cognate MHCligands can theoretically lead to alloreactivity potential against the graft (fig. 1). Recent publications have shown a correlation between specific KIR/HLA-C and graft survival in kidney and liver transplantation [32, 33]. However, these data were not systematically retrieved [34, 35]. The opposing 


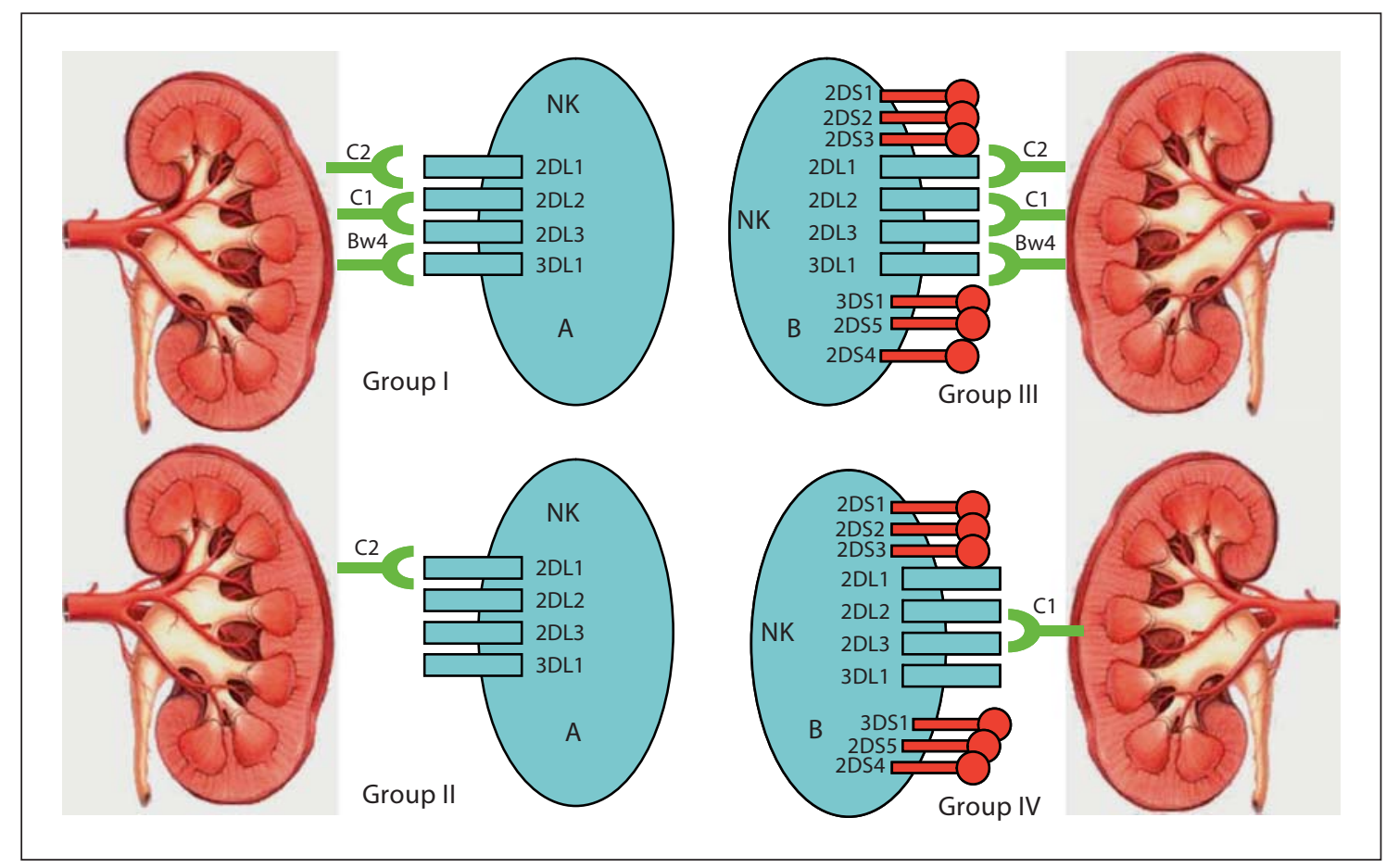

Fig. 1. NK cell alloreactivity in SOT. The KIR/HLA combination can lead to several alloreactivity potentials. Group I is characterized by inhibitory KIRs only (haplotype A) and 3 donor ligands, suggesting a weak NK cell alloreactivity potential. Group II is characterized by inhibitory KIRs but only 1 donor ligand, suggesting an intermediate NK cell alloreactivity potential. Group III is characterized by activating and inhibitory KIRs (haplotye B) and 3 donor ligands, also suggesting an intermediate NK cell alloreactivity potential. Finally, group IV is characterized by activating and inhibitory KIRs and only 1 donor ligand, suggesting a strong NK cell alloreactivity potential. conclusions by these groups could be explained by the difference in the design of the cohorts and the quality of KIR/HLA typing, also highlighting the complexity of the HLA-NK cell interactions as well as the pitfalls of the studies based on genetic polymorphisms.

In addition, the MHC genotype of the recipient (selfMHC, not represented in fig. 1) could be important in order to reach functional maturity of the NK cells. This requirement for self-MHC-specific KIR has been termed 'licensing' [36]. A patient with NK cells licensed for KIR2DL2/3 may not benefit from receiving an organ from a donor with HLA-C specific to KIR2DL1. The licensing of NK cells depends on KIR/HLA-C specificity, which itself can vary widely among populations. Therefore, the model can be much more complex in predicting the KIR-HLA alloreactivity against the transplanted organ.

Although NK cells in peripheral blood account for 10 $15 \%$ of lymphocytes, hepatic NK cells comprise $30-40 \%$ of all lymphocytes present in the normal adult liver. A study on NK cells from liver grafts (NK cells of donor origin) has demonstrated that hepatic NK cells are enriched for CD56 ${ }^{\text {bright }}$ cells, which represent about $50 \%$ of the total liver NK cell population. The NK cells from the donor mix with the recirculating pool of recipient NK cells for approximately 2 weeks. This CD56 ${ }^{\text {bright }}$ population was characterized by a high activation state and killed K562 target cells more efficiently than blood NK cells. These data suggest that upon encounter with the recipient immune system, either within the graft or in recipient tissues, NK cells may inhibit the recipient's response to the liver graft by killing recipient APCs or T cells [37].

Lung transplantation is also of interest because intragraft NK cells can be studied in bronchoalveolar lavage. After lung transplantation, NK cells in bronchoalveolar lavage are shown to have a greater proportion of CD56 $6^{\text {bright }}$ cells, expressing less KIRs, and demonstrated an activated phenotype. In clinically stable recipients, peripheral blood NK cells were not activated; however, this 
contrasted markedly with a small subset of patients experiencing acute allograft rejection whose NK cells demonstrated a more activated profile (high expression of CD25, LAMP-1, HLA-DR and Nkp44) [38].

The influence of immunosuppressive drugs on NK cell reactivity is of great importance in SOT. Due to distinct experimental designs, in vitro studies have shown contradictory results with respect to the functional activity of NK cells after treatment. Two historical studies conducted in vitro revealed the inhibition of NK cell cytotoxicity on target cells in the presence of cyclosporin A, but only after treating cells with drugs for $\geq 8 \mathrm{~h} \mathrm{[39].} \mathrm{A} \mathrm{third}$ study found cyclosporine A to have no effect [40]. More recently, cyclosporine A was shown to increase cytotoxicity, an effect attributed to an alteration in levels of NK receptor expression [41]. In a rat model of liver transplantation, cyclosporine A and tacrolimus spared NK cells. This suggests that NK cells might continue to eliminate virally infected or transformed cells in transplanted patients. In contrast, proliferation and function of NK cells were diminished by rapamycin [42]. Recent data suggest that calcineurin inhibitors enhance NK functions - or at least have no inhibitory activity on NK cells, in contrast to T cells [43].

In vivo, $\mathrm{NK}$ innate immune effector cells and their cytotoxicity were preserved to a greater extent in a regimen of tacrolimus and mycophenolate mofetil than they were with cyclosporine A and azathioprine 12 months after kidney transplantation [44]. We recently demonstrated that even in the presence of polyclonal anti-thymoglobuline antibody that depleted $\mathrm{T}$ and NK cells transiently, the NK cell function is preserve after kidney transplantation. The importance of NK cell subpopulations expressing different numbers of KIRs and C-type lectins demonstrated the interest to study not only the genotype but also the phenotype of NK cell receptors after SOT [45].

\section{NK Cells and Virus after SOT}

Cytomegalovirus (CMV) reactivation is a major problem after kidney transplantation, and recent data suggested an important role of NK cells in the control of viral infection/reactivation in immunosuppressed patients. We reported an extensive study comparing the genotype of KIR genes and their MHC cognate ligands with the rate of CMV infection in kidney transplant recipients [46]. The recipients with a strong activating profile [i.e. absence of HLA-C ligand to inhibitory KIR (missing KIR ligand) and/or the presence of numerous activating KIR genes] were both associated with a lower rate of CMV infection in the first months after transplantation. During this period of time, immunosuppression was high, leading to a high risk of severe CMV infection/reactivation. In addition, during active CMV infection, the secretion of NK cell IFN- $\gamma$ was strongly reduced [46]. In liver transplantation for hepatitis-C-associated cirrhosis, the reactivation of the virus is a major problem. Recent data on a small cohort of patients suggest that the presence of KIR2DL3 in the recipient correlates with the progression to liver fibrosis. The mismatching of the HLA-KIR ligand favors the progression of recurrent hepatitis to fibrosis only in the presence of KIR2DL3. However, due to the small number of patients and multiple testing, the relevance of the results should be confirmed in a larger cohort. [47]. According to the biology of NK cells and KIRs which do not recognize specific antigens in the HLA-C ligand, it is questionable if a distinct KIR could be significantly relevant. Current data mainly suggest that the global activation/inhibitory state of the NK cells is associated with a reduction in the severity of the viral disease.

\section{NK Cells and Embryonic or Adult SCT}

Any tissue transplanted in a genetically unrelated individual would be subject to rejection by $\mathrm{T}$ cells without immunosuppression. As mentioned above, the role of NK cells with regard to the HLA/KIR status of the recipients/ tissue could have a significant impact on the mechanism of rejection. The enormous promise of stem cells to make tissues for medical therapies should be treated cautiously due to potential immune hurdles. Embryonic stem cells (ESCs) and their progenitors or mature cells derived from unrelated individuals are prone to rejection. The absence or low expression of MHC-I molecules at the cell surface of ESCs or ESC-derived cells is a potential risk, although nonexclusive, for NK cell cytotoxicity. Because most NK cell receptors that bind MHC ligands have an inhibitory function, the absence or weak expression of the classical MHC-I or nonclassical HLA-E, HLA-G or MICA in ESCs made such cells good targets for NK cell killing. However, a previous study demonstrated that irrespective of the differentiation status of the cells and the expression levels of MHC-I in vitro, ESCs were not killed by NK cells, even if the inhibitory molecules HLA-G were expressed [48]. Therefore, it has been suggested that ESCs were not killed by NK cells because of a lack of recognition, but rather because of inhibition [48]. Recent data demonstrated that neuronal precursor cells derived from ESCs were strong- 


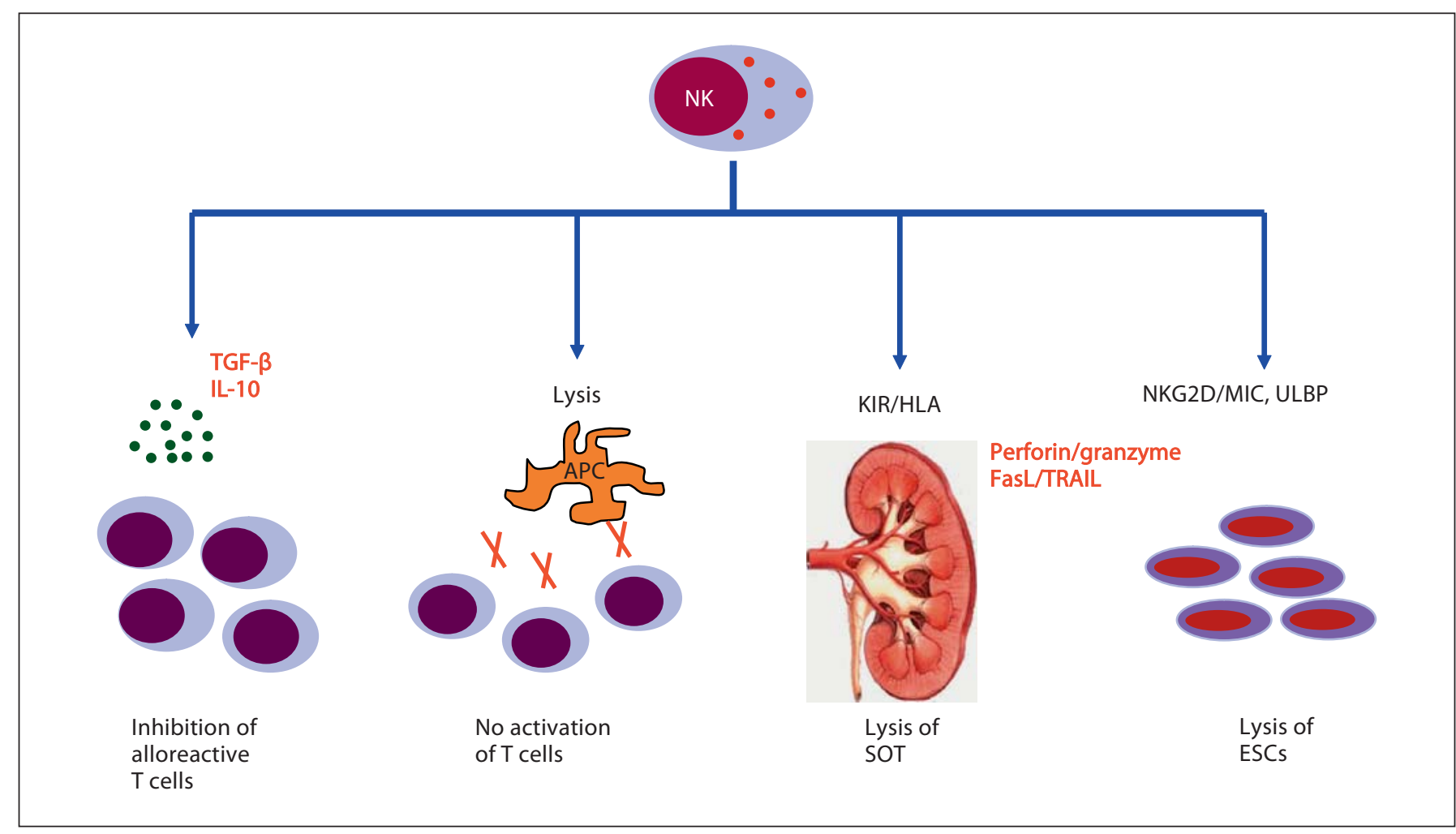

Fig. 2. NK cells are involved directly and indirectly to control the immune response after organ or tissue transplantation. Secretion of cytokines like TGF- $\beta$ and IL-10 by NK cells can inhibit alloreactive T cells. The killing of APCs can indirectly block T-cell activation. The direct killing of the organ or tissue like ESCs by NK cells is driven by different receptor/ligand combinations and is mediated by granzyme, perforin and the TRAIL/FasL pathways.

ly killed by NK cells by a mechanism that is MHC-I independent involving ligands of NKG2D, MICA/B and ULBP1, ULBP2 and ULBP3 [49]. Therefore, the potential of allogeneic stem cell therapy in transplantation should be tempered by immune reactivity mediated by $\mathrm{T}$ cells and NK cells.

\section{Conclusion}

After years of relative neglect in the field of SOT and tissue transplantation, NK cells are being recognized as active participants of the immune response against SOT or tissue transplantation by direct or indirect interaction (fig. 2). Immunosuppressive drugs appear to have a modest effect on NK cells which reinforce their role in the mechanism of rejection and as a key player of immune defense. Following allorecognition, activated NK cells acquire cytolytic effector functions and release a series of proinflammatory cytokines including IFN- $\gamma$ and
TNF- $\alpha$, and thus, develop the potential of contributing to the rejection of the solid organ allograft directly and/or indirectly by enhancing Th1-adaptive alloimmunity. NK cells appear to promote the acceptance of the allograft by killing donor professional APCs and by secreting immunoregulatory IL-10 cytokine, thereby leading to activation of Th2 and/or regulatory T-cell responses.

The antiviral activity of NK cells is of huge importance in the context of T-cell inhibition where the balance of activating and inhibitory receptors and their ligands seems to play a critical role. Interestingly, a recent study suggests that an NK cell subpopulation may have longlived memory when exposed to viral-infected cells [50]; it would be of major interest to investigate a similar phenotype with regard to alloreactivity against the graft.

While much work remains to be done in this emerging area of transplantation research, these recent findings suggest that manipulations of NK cells in humans may improve the long-term outcome for organ and tissue transplant patients. 


\section{References}

$>1$ Larosa DF, Rahman AH, Turka LA: The innate immune system in allograft rejection and tolerance. J Immunol 2007;178:75037509.

$>2$ Kärre K, Ljunggren HG, Piontek G, Kiessling $\mathrm{R}$ : Selective rejection of $\mathrm{H}$-2-deficient lymphoma variants suggests alternative immune defence strategy. Nature 1986;319:675-678.

-3 Uehara S, Chase CM, Kitchens WH, Rose HS, Colvin RB, Russell PS, Madsen JC: NK cells can trigger allograft vasculopathy: the role of hybrid resistance in solid organ allografts. J Immunol 2005;175:3424-3430.

4 Oertel M, Kohlhaw K, Diepolder HM, Schroder S, Schwarz R, Tannapfel A, Mossner J, Hauss J, Berr F: Alloreactivity of natural killer cells in allogeneic liver transplantation. Transplantation 2001;72:116-122.

$>5$ Wei XH, Orr HT: Differential expression of HLA-E, HLA-F, and HLA-G transcripts in human tissue. Hum Immunol 1990;29:131142.

$>6$ Lanier LL: NK cell recognition. Annu Rev Immunol 2005;23:225-274.

$>7$ Parham P: The genetic and evolutionary balances in human NK cell receptor diversity. Semin Immunol 2008;20:311-316.

$>8$ Parham P: MHC class I molecules and KIRs in human history, health and survival. Nat Rev Immunol 2005;5:201-214.

$>9$ Suarez-Alvarez B, Lopez-Vazquez A, Baltar JM, Ortega F, Lopez-Larrea C: Potential role of NKG2D and its ligands in organ transplantation: new target for immunointervention. Am J Transplant 2009;9:251-257.

$>10$ Moretta A, Bottino C, Vitale M, Pende D, Cantoni C, Mingari MC, Biassoni R, Moretta L: Activating receptors and coreceptors involved in human natural killer cell-mediated cytolysis. Annu Rev Immunol 2001;19:197223.

-11 de Rham C, Ferrari-Lacraz S, Jendly S, Schneiter G, Dayer JM, Villard J: The proinflammatory cytokines IL-2, IL-15 and IL-21 modulate the repertoire of mature human natural killer cell receptors. Arthritis Res Ther 2007; 9:R125.

12 Ruggeri L, Capanni M, Urbani E, Perruccio K, Shlomchik WD, Tosti A, Posati S, Rogaia D, Frassoni F, Aversa F, Martelli MF, Velardi A: Effectiveness of donor natural killer cell alloreactivity in mismatched hematopoietic transplants. Science 2002;295:2097-2100.

13 Lundqvist A, McCoy JP, Samsel L, Childs R: Reduction of GVHD and enhanced antitumor effects after adoptive infusion of alloreactive Ly49-mismatched NK cells from MHC-matched donors. Blood 2007; 109: 3603-3606.

14 Caligiuri MA, Velardi A, Scheinberg DA, Borrello IM: Immunotherapeutic approaches for hematologic malignancies. Hematology Am Soc Hematol Educ Program 2004; 337-353.
15 Ruggeri L, Capanni M, Casucci M, Volpi I, Tosti A, Perruccio K, Urbani E, Negrin RS, Martelli MF, Velardi A: Role of natural killer cell alloreactivity in HLA-mismatched hematopoietic stem cell transplantation. Blood 1999;94:333-339.

16 Giebel S, Locatelli F, Lamparelli T, Velardi A, Davies S, Frumento G, Maccario R, Bonetti F, Wojnar J, Martinetti M, Frassoni F, Giorgiani G, Bacigalupo A, Holowiecki J: Survival advantage with KIR ligand incompatibility in hematopoietic stem cell transplantation from unrelated donors. Blood 2003;102: 814-819.

17 Ruggeri L, Mancusi A, Capanni M, Martelli MF, Velardi A: Exploitation of alloreactive NK cells in adoptive immunotherapy of cancer. Curr Opin Immunol 2005;17:211-217.

18 Hsu KC, Keever-Taylor CA, Wilton A, Pinto C, Heller G, Arkun K, O’Reilly RJ, Horowitz MM, Dupont B: Improved outcome in HLAidentical sibling hematopoietic stem-cell transplantation for acute myelogenous leukemia predicted by KIR and HLA genotypes. Blood 2005;105:4878-4884.

19 Schaffer M, Malmberg KJ, Ringden O, Ljunggren HG, Remberger M: Increased infection-related mortality in KIR-ligand-mismatched unrelated allogeneic hematopoietic stem-cell transplantation. Transplantation 2004;78:1081-1085.

20 Katz G, Gazit R, Arnon TI, Gonen-Gross T, Tarcic G, Markel G, Gruda R, Achdout H, Drize O, Merims S, Mandelboim O: MHC class I-independent recognition of NK-activating receptor KIR2DS4. J Immunol 2004; 173:1819-1825.

21 McNerney ME, Lee KM, Zhou P, Molinero L, Mashayekhi M, Guzior D, Sattar H, Kuppireddi S, Wang CR, Kumar V, Alegre ML: Role of natural killer cell subsets in cardiac allograft rejection. Am J Transplant 2006;6: 505-513.

22 Yu G, Xu X, Vu MD, Kilpatrick ED, Li XC: NK cells promote transplant tolerance by killing donor antigen-presenting cells. J Exp Med 2006;203:1851-1858.

23 De Maria A, Fogli M, Mazza S, Basso M, Picciotto A, Costa P, Congia S, Mingari MC, Moretta L: Increased natural cytotoxicity receptor expression and relevant IL-10 production in NK cells from chronically infected viremic HCV patients. Eur J Immunol 2007; 37:445-455.

24 Ghiringhelli F, Menard C, Terme M, Flament C, Taieb J, Chaput N, Puig PE, Novault S, Escudier B, Vivier E, Lecesne A, Robert C, Blay JY, Bernard J, Caillat-Zucman S, Freitas A, Tursz T, Wagner-Ballon O, Capron C, Vainchencker W, Martin F, Zitvogel L: CD4+CD25+ regulatory T cells inhibit natural killer cell functions in a transforming growth factor-beta-dependent manner. J Exp Med 2005;202:1075-1085.
25 Markus PM, van den BM, Cai X, Harnaha J, Palomba L, Hiserodt JC, Cramer DV: Effect of selective depletion of natural killer cells on allograft rejection. Transplant Proc 1991;23: 178-179.

-26 Heidecke CD, Araujo JL, Kupiec-Weglinski JW, Abbud-Filho M, Araneda D, Stadler J, Siewert J, Strom TB, Tilney NL: Lack of evidence for an active role for natural killer cells in acute rejection of organ allografts. Transplantation 1985;40:441-444.

27 Maier S, Tertilt C, Chambron N, Gerauer K, Huser N, Heidecke CD, Pfeffer K: Inhibition of natural killer cells results in acceptance of cardiac allografts in CD28-/- mice. Nat Med 2001;7:557-562.

-28 Kroemer A, Xiao X, Degauque N, Edtinger K, Wei H, Demirci G, Li XC: The innate NK cells, allograft rejection, and a key role for IL-15. J Immunol 2008;180:7818-7826.

29 Kitchens WH, Uehara S, Chase CM, Colvin RB, Russell PS, Madsen JC: The changing role of natural killer cells in solid organ rejection and tolerance. Transplantation 2006; 81:811-817.

30 Van der Touw W, Bromberg JS: Natural killer cells and the immune response in solid organ transplantation. Am J Transplant 2010; 10:1354-1358.

-31 Hidalgo LG, Sis B, Sellares J, Campbell PM, Mengel M, Einecke G, Chang J, Halloran PF: NK cell transcripts and NK cells in kidney biopsies from patients with donor-specific antibodies: evidence for NK cell involvement in antibody-mediated rejection. Am J Transplant 2010;10:1812-1822.

-32 Hanvesakul R, Spencer N, Cook M, Gunson B, Hathaway M, Brown R, Nightingale P, Cockwell P, Hubscher SG, Adams DH, Moss $\mathrm{P}$, Briggs D: Donor HLA-C genotype has a profound impact on the clinical outcome following liver transplantation. Am J Transplant 2008;8:1931-1941.

33 Kunert K, Seiler M, Mashreghi MF, Klippert K, Schonemann C, Neumann K, Pratschke J, Reinke P, Volk HD, Kotsch K: KIR/HLA ligand incompatibility in kidney transplantation. Transplantation 2007;84:1527-1533.

-34 Tran TH, Middleton D, Dohler B, Scherer S, Meenagh A, Sleator C, Opelz G: Reassessing the impact of donor HLA-C genotype on long-term liver transplant survival. Am J Transplant 2009;9:1674-1678.

-35 Tran TH, Mytilineos J, Scherer S, Laux G, Middleton D, Opelz G: Analysis of KIR ligand incompatibility in human renal transplantation. Transplantation 2005;80:11211123.

36 Kulkarni S, Martin MP, Carrington M: The Yin and Yang of HLA and KIR in human disease. Semin Immunol 2008;20:343-352. 
37 Moroso V, Metselaar HJ, Mancham S, Tilanus HW, Eissens D, van Der Meer A, van der Laan LJ, Kuipers EJ, Joosten I, Kwekkeboom $\mathrm{J}$ : Liver grafts contain a unique subset of natural killer cells that are transferred into the recipient after liver transplantation. Liver Transpl 2010;16:895-908.

38 Meehan AC, Sullivan LC, Mifsud NA, Brooks AG, Snell GI, Kotsimbos TC, Westall GP: Natural killer cell activation in the lung allograft early posttransplantation. Transplantation 2010;89:756-763.

39 Wasik M, Gorski A, Stepien-Sopniewska B, Lagodzinski Z: Effect of FK506 versus cyclosporine on human natural and antibody-dependent cytotoxicity reactions in vitro. Transplantation 1991;51:268-270.

-40 Shao-Hsien C, Lang I, Gunn H, Lydyard P: Effect of in vitro cyclosporin. A treatment on human natural and antibody-dependent cell-mediated cytotoxicity. Transplantation 1983;35:127-129.

41 Wang H, Grzywacz B, Sukovich D, McCullar V, Cao Q, Lee AB, Blazar BR, Cornfield DN, Miller JS, Verneris MR: The unexpected effect of cyclosporin A on CD56+. Blood 2007; 110:1530-1539.

42 Wai LE, Fujiki M, Takeda S, Martinez OM, Krams SM: Rapamycin, but not cyclosporine or FK506, alters natural killer cell function. Transplantation 2008;85:145-149.
43 Eissens DN, Van Der Meer A, Van Cranenbroek B, Preijers FW, Joosten I: Rapamycin and MPA, but not CsA, impair human NK cell cytotoxicity due to differential effects on NK cell phenotype. Am J Transplant 2010; 10:1981-1990.

44 Vacher-Coponat H, Brunet C, Moal V, Loundou A, Bonnet E, Lyonnet L, Ravet S, Sampol-Manos E, Sampol J, Berland Y, George FD, Paul P: Tacrolimus/mycophenolate mofetil improved natural killer lymphocyte reconstitution one year after kidney transplant by reference to cyclosporine/azathioprine. Transplantation 2006;82:558-566.

45 Hadaya K, Avila Y, Valloton L, de Rham C, Bandelier C, Ferrari-Lacraz S, Pascual M, Pantaleo G, Martin PY, Buhler L, Villard J: Natural killer cell receptor - repertoire and functions after induction therapy by polyclonal rabbit anti-thymocyte globulin in unsensitized kidney transplant recipients. Clin Immunol 2010;137:250-260.
46 Hadaya K, de Rham C, Bandelier C, Bandelier C, Ferrari-Lacraz S, Jendly S, Berney T, Buhler L, Kaiser L, Seebach JD, Tiercy JM, Martin PY, Villard J: Natural killer cell receptor repertoire and their ligands, and the risk of CMV infection after kidney transplantation. Am J Transplant 2008;8:2674-2683.

47 Askar M, Avery R, Corey R, Lopez R, Thomas D, Pidwell D, Eghtesad B, Miller C, Fung J, Zein NN: Lack of killer immunoglobulinlike receptor 2DS2 (KIR2DS2) and KIR2DL2 is associated with poor responses to therapy of recurrent hepatitis $C$ virus in liver transplant recipients. Liver Transpl 2009;15:15571563.

48 Odeberg J, Piao JH, Samuelsson EB, Falci S, Akesson E: Low immunogenicity of in vitroexpanded human neural cells despite high MHC expression. J Neuroimmunol 2005; 161:1-11.

49 Preynat-Seauve O, de Rham C, Tirefort D, Ferrari-Lacraz S, Krause KH, Villard J: Neural progenitors derived from human embryonic stem cells are targeted by allogeneic $\mathrm{T}$ and natural killer cells. J Cell Mol Med 2009. 13:3556-3569.

50 Sun JC, Beilke JN, Lanier LL: Adaptive immune features of natural killer cells. Nature 2009;457:557-561. 